\title{
Development of lornoxicam multiparticulate sustained release drug delivery system using copal gum-pectin and optimization by applying central composite design
}

\author{
Mulchand SHENDE 1* (D), Priya DESHMUKH 2 (D) \\ 1 Government College of Pharmacy, Pharmaceutics Department, Kathora Naka, Amravati, Maharashtra- 444604, \\ India. \\ 2 Government College of Pharmacy, Quality Assurance Department, Kathora Naka, Amravati, Maharashtra- 444604, \\ India. \\ * Corresponding author. E-mail: shende_mulchand@rediff.com (M.S.); Tel. +91-771-991 9955.
}

Received: 11 May 2020 / Revised: 11 July 2020 / Accepted: 16 July 2020

\begin{abstract}
The purpose of the present study was to explore the scope of natural gum to control the drug releases and develop multiparticulate sustained drug delivery system for lornoxicam. Lornoxicam pellets were prepared using copal gum and pectin as natural release retarding polymers by extrusion and spheronization. A central composite design was employed as copal gum (X1) and pectin (X2) independent variables to optimize the lornoxicam pellets in terms of sustained release, production yield, sphericity, and flowability. The response (Y1) as percentage drug releases at $10 \mathrm{~h}$, (Y2) time (t50) required to $50 \%$ drug release, (Y3) \% yield and (Y4) average pellets size were measured for each trial and statistical equations with significant interaction terms were derived to predict relation. All the batches have excellent flow properties with angle of repose in the range of $11.57 \pm 0.33^{\circ}$ to $15.94 \pm 0.84^{\circ}$, and carr's index and hausner's ratio in the range of $10.17 \pm 1.34 \%$ to $15.97 \pm 1.62 \%$ and $1.11 \pm 0.04$ to $1.19 \pm 0.09$, respectively. The drug release studies indicated that as the concentrations of polymers increases the drug release decreases, producing sustained release of lornoxicam. Among the multiparticulate batches, batch F7 was found to be optimized based on the criteria of attaining the minimum particle size $(<871.49 \mu \mathrm{m})$, the maximum value of drug released Q10 of $83.20 \%$, t50 of $5.13 \mathrm{~h}$, percent yield of $67.52 \%$ and particle size of $820.24 \mu \mathrm{m}$. The sustained release pellets showed hixon-crowell model as best fit model and follow anomalous kinetics (non-fickian transport) for drug release.
\end{abstract}

KEYWORDS: Lornoxicam; pellets; copal gum; pectin; central composite design.

\section{INTRODUCTION}

Multiparticulate drug delivery system is generally used for oral route of drug administration contain multiple numbers of small separate units and exhibits different characteristics. In this, the dose of the drug is divided in to several subunits and consists of a number of sphere-shaped particles (diameter 0.05-2.00 $\mathrm{mm}$ ). The dosage forms like granules, micro spheres, pellets, spheroids, mini tablets comes under multiparticulate drug delivery system. The multiparticulate drug delivery system is expected to formulate since it shows the different mechanism of action, gives an additive or synergistic effect, and also reduces the doses of individual agents and limited side effects. There are various advantages of multiparticulate drug delivery system over single unit dosage form. It helps to avoid dose dumping and gives fast gastric empty effect. It gives better distribution and also causes less irritation. Formulation provides stability and unique release pattern to increase the bioavailability. This system may have some drawbacks like low drug loading, high need of excipients, multiple formulation steps and sometimes high cost of production [1]. Sustained release film coated tablet is available in market, but there are possibilities of dose dumping which leads to poor bioavailability due to small intestine absorption site. Therefore considering various advantages of multiparticulate drug delivery system over tablets helps to better drug distribution, less irritation, more stability and unique release pattern for increase bioavailability.

How to cite this article: Shende M, Deshmukh P. Development of lornoxicam multiparticulate sustained release drug delivery system using copal gum-pectin and optimization by applying central composite design. J Res Pharm. 2020; 24(5): 708-719. 
In the development of a sustained release drug delivery system, an important issue is to optimize formulation with an appropriate dissolution rate in a short time period and minimum trials. Optimization of formulation design can be used in development of pharmaceutical products due to the wide array of parameters and variables that must be controlled to achieve desire release pattern and meet other performance criteria. Many statistical experimental designs have been recognized as useful techniques to optimize the process variables. For this purpose, response surface methodology (RSM) includes central composite design (CCD) is widely used when only a few significant factors are involved in experimental optimization. The technique requires less experimentation and time as a result proving far more effective and cost-effective than the conventional methods [2].

Lornoxicam is a non-steroidal anti-inflammatory drug, comes under oxicam class and is a congener of tenoxicam with analgesic property [3]. Mode of action of lornoxicam is an inhibition of prostaglandins and throboxane synthesis by inhibiting cyclooxygenase enzymes but it do not inhibit the 5-lipo oxygenase. It has $30 \%-40 \%$ bioavailability with a plasma half-life of 3 to $4 \mathrm{~h}$, thus requiring multiple dosing to maintain adequate plasma concentration during treatment [4-5]. Lornoxicam is also poorly absorbed from the upper part of the gastrointestinal tract and it is well absorbed from the small intestine. The solubility of lornoxicam in water is $\mathrm{pH}$-dependent, increasing sharply with increasing $\mathrm{pH}$ above 5 . It has very poor solubility in the acidic conditions (stomach) and hence, the contact time with the stomach mucosa increases which may cause irritation and leads to ulceration. So to reduce the contact with stomach mucosa, it is formulated as sustained release using natural polymers [6]. The use of natural polymers for pharmaceutical applications is attractive because they are readily available, relatively inexpensive, nontoxic, stable, and potentially degradable and compatible due to their natural origin.

Sustained release film coated and matrix tablets are available in market, but there are possibilities of dose dumping which leads to poor bioavailability due to small intestine absorption site [7-8]. Therefore considering various advantages of multiparticulate drug delivery system over tablets helps to better drug distribution, less irritation, more stability and unique release pattern for increase bioavailability. In the design of sustained and controlled release drug delivery systems, release-retarding polymers play an important role by controlling release of the drug from the systems. Various natural polymers are used for sustained release formulations including xanthan gum, pectin, okra gum, lactose, copal gum, chitosan and locust bean gum [910]. The present study was aimed to developing sustained release pellets of lornoxicam using copal gum and pectin as release retarding polymers in aspect to provide effective treatment for rheumatoid arthritis. The effect of natural polymers on sustainability of lornoxicam and pellets were evaluated and optimized in terms of pellets size analysis and drug release properties.

\section{RESULTS AND DISCUSSION}

In the present study, multiparticulate sustain release drug delivery system is developed and optimized by central composite design by utilizing copal gum and pectin as natural polymers exhibited less percentage deviation of response parameters from both predicted and target responses in comparison to other formulations. The UV spectroscopy method was selected for lornoxicam to calculate the percent yield and percent (\%) release data of prepared formulation. The standard calibration curve was prepared using concentration range $5-30 \mu \mathrm{g} / \mathrm{ml}$, analyzed regression analysis and $\mathrm{r}^{2}$ value was 0.998 which indicated that the data was very close to the fitted regression line.

\subsection{Fourier transform infrared spectrum}

The IR spectrum of lornoxicam, copal gum, and pectin along with their physical mixtures was obtained by fourier transform infrared (FTIR) as shown in Figure 1. The interpretations of the IR frequencies were done and the absorption bands were consistent with the structure of lornoxicam, copal gum and pectin. The FTIR spectrum of pure drug showed functional peaks at 3066 to 1636, 1388, 1330, 1423, 1543, and $1600 \mathrm{~cm}^{-1}$. The copal gum spectra showed peaks at 1597, 1639, and 790, while the physical mixture showed peaks at 3066, $1636,1543,1612,1427,1388,1330$, and $783 \mathrm{~cm}^{-1}$ with negligible shift in wave number [10]. From the spectra of physical mixtures, all spectra showed peaks in the range of 3066 to $3070 \mathrm{~cm}^{-1}$ and $1636 \mathrm{~cm}^{-1}$ to $1639 \mathrm{~cm}^{-1}$ indicated the presence of $-\mathrm{NH}$ group and primary amide group respectively. All the mixtures showed absorbance peak between 1543 to $1612 \mathrm{~cm}^{-1}$ indicated the secondary amide. The peaks for $\mathrm{SO}_{2}$ were also retained in all the spectra of physical mixtures. The presence of alkyl halide group in the mixtures was observed the sharp peaks between the ranges of 833 to $837 \mathrm{~cm}^{-1}$. Frequencies of functional groups of pure drug remained intact in physical mixture containing different polymers; these results confirmed that, no interaction 
occurred between lornoxicam and polymers on mixing. The peaks obtained in the spectrum of all samples correlates with the peaks of drug spectrum and were identical with the peaks of pure drug and physical mixture of drug and polymers and pure drug with all other excipients mixture which ensured that there was no any chemical interaction between them.

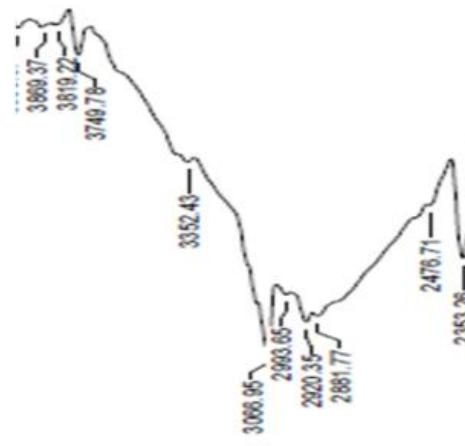

a)
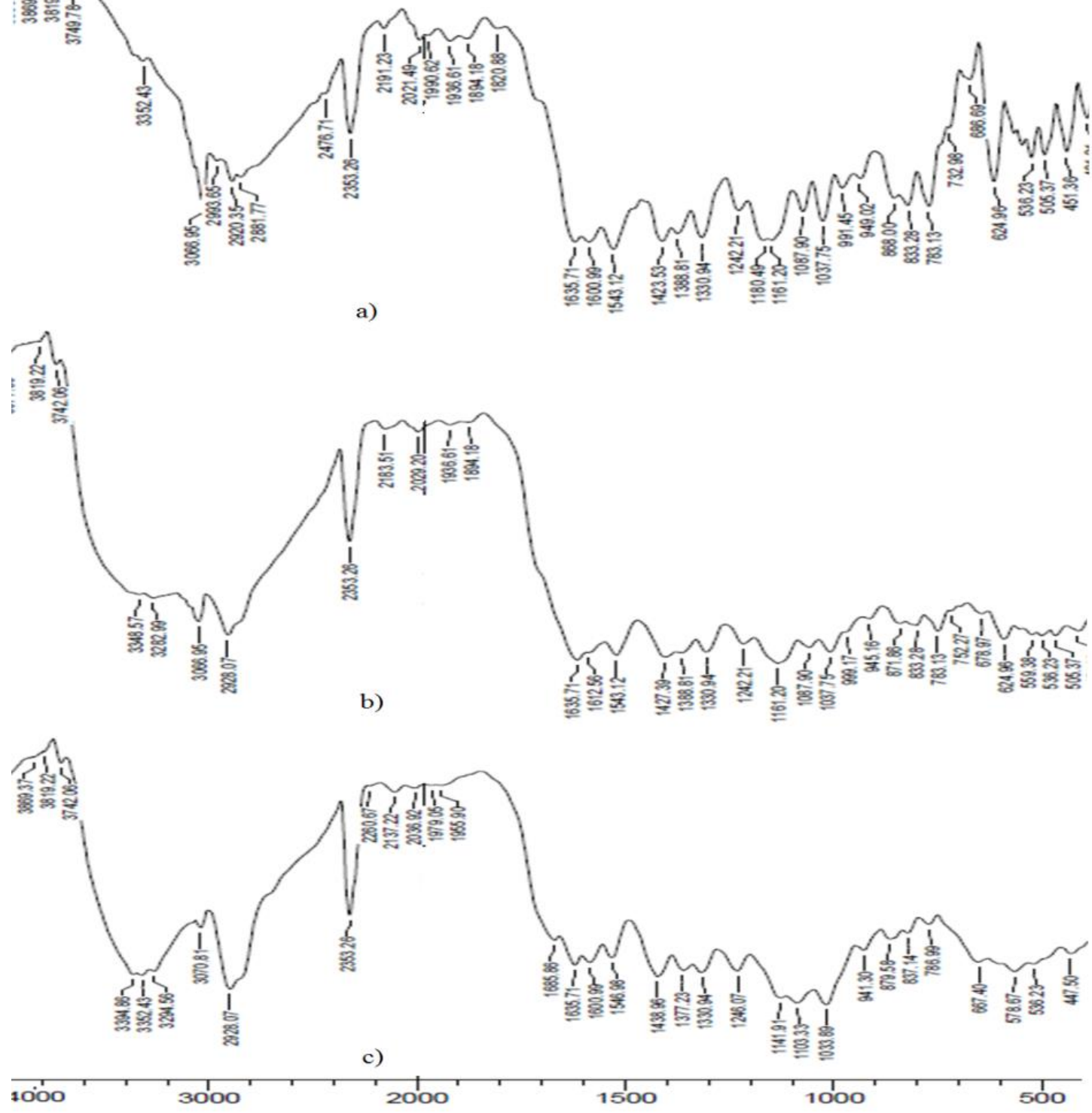

Figure 1. FTIR spectra a) Lornoxicam, b) Physical mixture of lornoxicam, copal gum and pectin, c) Physical mixture of lornoxicam, polymers and excipients.

\subsection{Preparation and characterization of lornoxicam sustained release pellets}

The lornoxicam pellets were prepared using wet granulation by extrusion and spheronization. The composition of factorial design batches are shown in Table 1. The experiments consisted of 9-run central composite design points generated to optimize levels of variables in the pellet formulations with the aid of Design-Expert ${ }^{\circledR} V 7$ software. The selected independent variables were amounts of copal gum $\left(\mathrm{X}_{1}\right)$, and of pectin $\left(\mathrm{X}_{2}\right)$ at three different levels, namely -alpha, center point, and +alpha level is coded as +1 and -1 respectively (Table 1). The various physical parameters like bulk density, tapped density, carr's index, hausner's ratio, angle of repose were tested to interpret the feasibility of pellets for solid dosage forms. The micromeritics parameters of pellets for all the formulations were shown in Table 2. From the results, $F_{1}$ and $F_{2}$ showed highest bulk and tapped density which may be due to the size of pellets and highest circularity. From the physical characterization of pellets, it was clearly observed that all the batches have excellent flow 
properties, with an angle of repose in the range $11.57 \pm 0.33^{\circ}$ to $15.945 \pm 0.84^{\circ}$ and carr's index and hausner's ratio in the range of $10.17 \pm 1.34 \%$ to $15.97 \pm 1.62 \%$ and $1.11 \pm 0.04$ to $1.19 \pm 0.09$, respectively (Table 2 ). The densities of material give an insight on the packaging and arrangement of the particles and the compaction profiles of the material. The settling of natural polymers within the void spaces of microcrystalline cellulose (MCC) makes the matrix pellets denser. From the powder characteristic i.e. angle of repose, compressibility index and hausner's ratio, it was concluded that the powder possesses good to excellent flow characteristics.

Table 1. Composition of pellets formulation using central composite design.

\begin{tabular}{|c|c|c|c|c|}
\hline \multirow[b]{2}{*}{ Batch } & \multicolumn{4}{|c|}{ Compositions (g) } \\
\hline & Lornoxicam & Copal gum & Pectin & MCC \\
\hline $\mathbf{F}_{1}$ & 0.66 & 1.50 & 1.00 & 1.84 \\
\hline $\mathbf{F}_{2}$ & 0.66 & 1.00 & 1.50 & 1.84 \\
\hline$F_{3}$ & 0.66 & 1.50 & 1.71 & 1.13 \\
\hline $\mathbf{F}_{4}$ & 0.66 & 1.50 & 0.29 & 2.55 \\
\hline $\mathbf{F}_{5}$ & 0.66 & 2.21 & 1.00 & 1.13 \\
\hline$F_{6}$ & 0.66 & 2.00 & 0.50 & 1.84 \\
\hline $\mathbf{F}_{7}$ & 0.66 & 2.00 & 1.50 & 0.84 \\
\hline $\mathrm{F}_{8}$ & 0.66 & 1.00 & 0.50 & 2.84 \\
\hline $\mathbf{F}_{9}$ & 0.66 & 0.79 & 1.00 & 2.55 \\
\hline \multicolumn{3}{|c|}{ Independent variables \& levels } & Low $(-1)$ & High $(+1)$ \\
\hline \multicolumn{3}{|c|}{ Concentration of copal gum $\left(X_{1}\right)$} & 1 & 2 \\
\hline \multicolumn{3}{|c|}{ Concentration of Pectin $\left(X_{2}\right)$} & 0.50 & 1.50 \\
\hline
\end{tabular}

Particle size is very important aspect in the study of drug release parameter. While studying drug release of any formulation one relation should be taken into consideration that smaller the particle size, faster will be the drug release or vice versa. Likewise, smaller and uniform pellet size will help to assure more homogenous drug release. By using sieve analysis, pellets size of all batches $\left(\mathrm{F}_{1}-\mathrm{F}_{9}\right)$ was found in the range of 752.57 to $990.42 \mu \mathrm{m}$. The particle size distribution analysis of pellets indicates a narrow size distribution in which most of the pellets were in the size range of 500 to $1000 \mu \mathrm{m}$. The evaluation studies on pellets for all the formulations were proved to be within limits and shown good derived and flow properties. Hence $10 \%$ solution of PEG 4000 was used as plasticizer and granulating fluid to maintain plasticity of pellets during the step of spheronization. The friability was in the range of $0.20 \pm 0.14$ to $0.90 \pm 0.14 \%$ (Table 2 ).

Table 2. Micromeritics properties and post formulation parameter of batches F1 to F9.

\begin{tabular}{|c|c|c|c|c|c|c|c|c|c|}
\hline Batch & $F_{1}$ & $F_{2}$ & $F_{3}$ & $F_{4}$ & $F_{5}$ & $F_{6}$ & $\mathbf{F}_{7}$ & $F_{8}$ & $F_{9}$ \\
\hline $\begin{array}{l}\text { Bulk Density* } \\
(\mathrm{g} / \mathrm{ml})\end{array}$ & $\begin{array}{c}0.677 \pm \\
0.17\end{array}$ & $\begin{array}{c}0.56 \pm \\
0.08\end{array}$ & $\begin{array}{l}0.452 \pm \\
0.05\end{array}$ & $\begin{array}{l}0.499 \\
\pm 0.06\end{array}$ & $\begin{array}{c}0.53 \\
\pm 0.16\end{array}$ & $\begin{array}{l}0.452 \\
\pm 0.03\end{array}$ & $\begin{array}{l}0.440 \\
\pm 0.03\end{array}$ & $\begin{array}{l}0.521 \\
\pm 0.02\end{array}$ & $\begin{array}{l}0.551 \\
\pm 0.03\end{array}$ \\
\hline $\begin{array}{l}\text { Tapped } \\
\text { Density* }(\mathrm{g} / \mathrm{ml})\end{array}$ & $\begin{array}{c}0.761 \pm \\
0.19\end{array}$ & $\begin{array}{c}0.654 \pm \\
0.13\end{array}$ & $\begin{array}{c}0.531 \pm \\
0.09\end{array}$ & $\begin{array}{c}0.589 \pm \\
0.13\end{array}$ & $\begin{array}{c}0.587 \pm \\
0.16\end{array}$ & $\begin{array}{c}0.538 \pm \\
0.05\end{array}$ & $\begin{array}{c}0.495 \pm \\
0.03\end{array}$ & $\begin{array}{c}0.605 \pm \\
0.03\end{array}$ & $\begin{array}{c}0.615 \pm \\
0.06\end{array}$ \\
\hline Carr's Index* & $\begin{array}{c}10.93 \pm \\
0.76\end{array}$ & $\begin{array}{c}13.91 \pm \\
0.45\end{array}$ & $\begin{array}{c}14.47 \pm \\
0.56\end{array}$ & $\begin{array}{c}14.48 \pm \\
0.75\end{array}$ & $\begin{array}{c}10.17 \pm \\
1.34\end{array}$ & $\begin{array}{c}15.87 \pm \\
0.78\end{array}$ & $\begin{array}{c}11.07 \pm \\
1.46\end{array}$ & $\begin{array}{c}15.97 \pm \\
1.62\end{array}$ & $\begin{array}{c}10.38 \pm \\
1.24\end{array}$ \\
\hline Hausner ratio* & $\begin{array}{c}1.12 \pm \\
0.01\end{array}$ & $\begin{array}{c}1.16 \pm \\
0.06\end{array}$ & $\begin{array}{c}1.17 \pm \\
0.08\end{array}$ & $\begin{array}{c}1.17 \pm \\
0.1\end{array}$ & $\begin{array}{c}1.11 \pm \\
0.04\end{array}$ & $\begin{array}{c}1.19 \pm \\
0.05\end{array}$ & $\begin{array}{c}1.12 \pm \\
0.03\end{array}$ & $\begin{array}{c}1.19 \pm \\
0.09\end{array}$ & $\begin{array}{l}1.12 \pm \\
0.03\end{array}$ \\
\hline $\begin{array}{l}\text { Angle of } \\
\text { repose* }^{*} \\
\left(\theta^{0}\right)\end{array}$ & $\begin{array}{c}11.57 \pm \\
0.33\end{array}$ & $\begin{array}{c}15.25 \pm \\
1.34\end{array}$ & $\begin{array}{c}14.16 \pm \\
1.64\end{array}$ & $\begin{array}{c}13.27 \pm \\
1.39\end{array}$ & $\begin{array}{c}14.24 \pm \\
0.69\end{array}$ & $\begin{array}{c}15.19 \pm \\
0.47\end{array}$ & $\begin{array}{c}11.66 \pm \\
0.19\end{array}$ & $\begin{array}{c}15.94 \pm \\
0.84\end{array}$ & $\begin{array}{c}12.19 \pm \\
1.09\end{array}$ \\
\hline $\begin{array}{l}\text { Particle size } \\
(\mu \mathrm{m})\end{array}$ & 752.57 & 837.21 & 920.82 & 990.12 & 818.02 & 990.41 & 814.57 & 895.94 & 830.44 \\
\hline$\%$ Yield & 79 & 60 & 72.2 & 80 & 70.4 & 80.8 & 67.2 & 81.6 & 80.2 \\
\hline Friability* (\%) & $0.9 \pm 0.1$ & $2.5 \pm 0.2$ & $0.2 \pm 0.5$ & $0.3 \pm 0.1$ & $0.2 \pm 0.1$ & $0.45 \pm 0.3$ & $0.4 \pm 0.1$ & $0.8 \pm 0.2$ & $0.65 \pm 0.4$ \\
\hline $\begin{array}{l}\text { Drug content* } \\
(\%)\end{array}$ & $\begin{array}{c}87.68 \pm \\
1.25\end{array}$ & $\begin{array}{c}90.62 \pm \\
1.06\end{array}$ & $\begin{array}{c}87.25 \pm \\
0.96\end{array}$ & $\begin{array}{c}88.75 \pm \\
1.47\end{array}$ & $\begin{array}{c}93.00 \pm \\
1.58\end{array}$ & $\begin{array}{c}95.12 \pm \\
0.25\end{array}$ & $\begin{array}{c}98.62 \pm \\
0.98\end{array}$ & $\begin{array}{c}98.87 \pm \\
0.78\end{array}$ & $\begin{array}{c}100.18 \pm \\
1.02\end{array}$ \\
\hline
\end{tabular}


Batch $\mathrm{F}_{8}$ showed maximum yield while batch $\mathrm{F}_{2}$ showed low yield. A higher spheronization speed and time causes decrease in sphericity and sizes of pellets and irregularity in shape and sizes causes decrease in production yield of the pellets. The drug content in all pellet formulations was found between $87.25 \pm 0.96$ and $100.18 \pm 1.02$, which indicated that the pellets have good reproducibility of drug content. All batches are within standard limits.

\subsection{In-vitro drug release and kinetics study}

The release pattern of lornoxicam from batches of pellets is graphically represented in Figure 2. From the in-vitro dissolution data, it was found that formulations $F_{1}$ to $F_{7}$ were 68.57 to $94.86 \%(10 \mathrm{~h}), 16.15$ to 37.78 $\%(2 \mathrm{~h})$ and 51.52 to $64.94 \%(5 \mathrm{~h})$ released of drug respectively, all the formulations showed better drug release profile for $10 \mathrm{~h}$ except $\mathrm{F}_{8}$ and $\mathrm{F}_{9}$ which liberation of drug $100 \%$ within $9 \mathrm{~h}$. Study of the in-vitro release profiles in potassium phosphate buffer ( $\mathrm{pH}$ 7.4) of the formulations showed that the variation in concentration of polymers from given batches $F_{1}$ to $F_{9}$ has variability on release rate of drug. It is clear that if the concentrations of polymers increase, drug release results are more significant to sustain for $10 \mathrm{~h} \mathrm{[11].}$

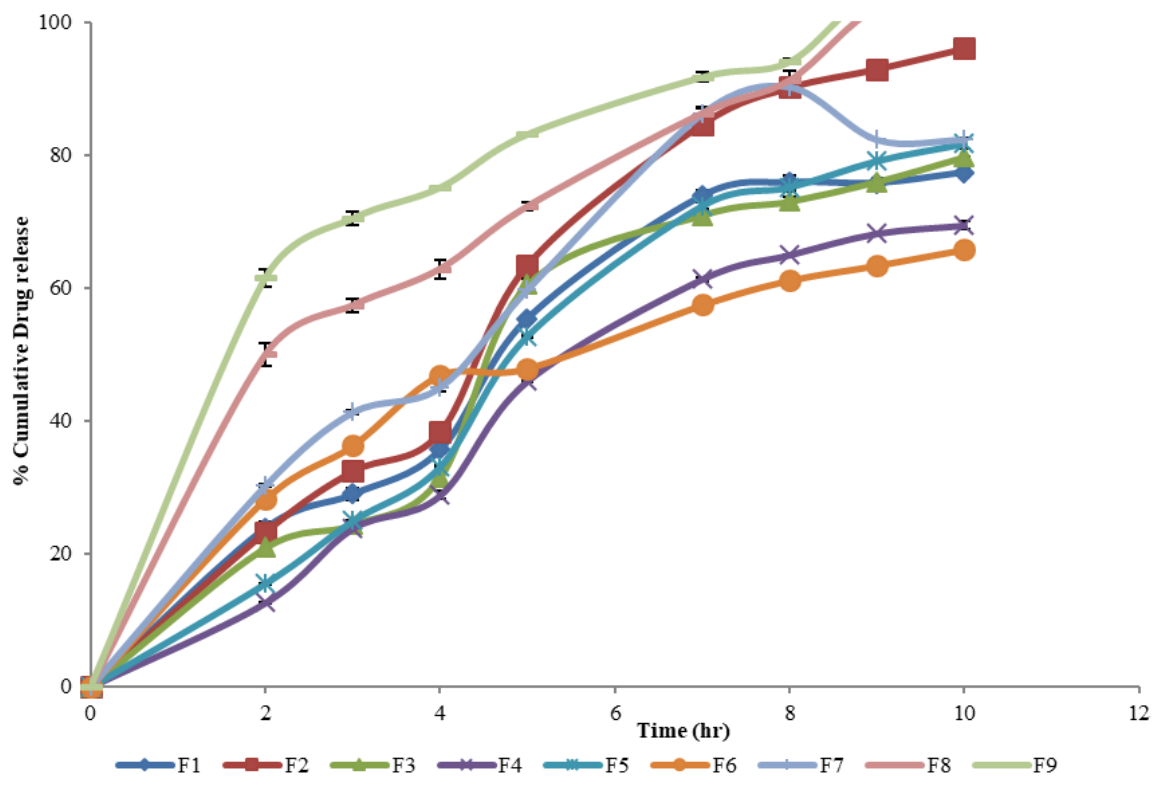

Figure 2. In-vitro drug release profile of lornoxicam sustained release pellets.

The formulation $\mathrm{F}_{7}$ containing $2 \mathrm{mg}$ copal gum and $1.5 \mathrm{mg}$ pectin showed the best results of drug release at $10 \mathrm{~h}$ may be due to the highest concentrations of both copal gum and pectin in their formulations. For an ideal modified-release dosage form should release the loading dose (25\%) in the first hour and the remaining drug $(75 \%)$ should be released at a constant rate, i.e., $6.8 \% / \mathrm{h}$ [12]. This ideal release pattern was considered as a reference release. Formulation $\mathrm{F}_{7}$ gave release profile close to the theoretical sustained release needed for lornoxicam. Batches $\mathrm{F}_{4}$ and $\mathrm{F}_{6}$ showed minimum drug release at $10 \mathrm{~h}$ may be due to the less concentration of pectin in both formulations which facilitate higher release.

All the prepared factorial formulations were studied for in-vitro drug release kinetics shown in Table 3. The release mechanism was assessed by comparing the values of the regression coefficient $\left(\mathrm{r}^{2}\right)$. All the prepared factorial formulations were studied for in-vitro drug release kinetics and found to be following five batches $F_{1}, F_{3}, F_{4}, F_{5}, F_{7}$ hixon-crowell model with highest $r^{2}$ value $\left(>r^{2}=0.969\right)$ while $F_{2}, F_{6}, F_{8}, F_{9}$ showed korsmeyer-peppas model with highest $r^{2}$ value $\left(>r^{2}=0.989\right)$. The value of exponent for the batches $F_{1}, F_{2}, F_{3}, F_{4}$, $\mathrm{F}_{5}$ and $\mathrm{F}_{7}$ was found $>0.5$ which indicated that the mechanism of drug release follow case II type of an anomalous non-fickian diffusion while batches $\mathrm{F}_{6}, \mathrm{~F}_{8}$ and $\mathrm{F}_{9}$ were $<0.5$ indicates quasi-fickian diffusion mechanism for drug release. This was a combination of diffusion as well as chain relaxation of the swelled polymers. The results indicate that the drug was released by a combination of diffusion as well as polymeric chain relaxation. This was a combination of diffusion as well as chain relaxation of the swelled polymers [13]. The $\mathrm{r}^{2}$ values of hixon-crowell as well as korsemeyer-peppas release pattern for all formulations were near one implying a mixed order kinetics being operative. In-vitro drug release study for proposed a sustained release of drug from microparticles indicating the efficient applicability of copal gum and pectin polymers in controlling the drug release of hydrophilic drugs. 
Table 3. In-vitro drug release kinetic study.

\begin{tabular}{cccccccl}
\hline \multirow{2}{*}{$\begin{array}{c}\text { Batch } \\
\text { Code }\end{array}$} & $\begin{array}{c}\text { Zero } \\
\text { order }\end{array}$ & $\begin{array}{c}\text { First } \\
\text { order }\end{array}$ & Higuchi & $\begin{array}{c}\text { Hixon- } \\
\text { crowell }\end{array}$ & Korsemeyer- peppas & \multirow{2}{*}{ Best fit model } \\
\cline { 2 - 6 } & $\mathbf{r}^{\mathbf{2}}$ & $\mathbf{r}^{\mathbf{2}}$ & $\mathbf{r}^{\mathbf{2}}$ & $\mathbf{r}^{\mathbf{2}}$ & $\mathbf{r}^{\mathbf{2}}$ & $\mathbf{n}$ & \\
\hline $\mathrm{F}_{1}$ & 0.8685 & 0.9664 & 0.9256 & $\mathbf{0 . 9 6 8 2}$ & 0.9498 & 0.659 & Hixon-crowell \\
$\mathrm{F}_{2}$ & 0.9382 & 0.9071 & 0.9068 & 0.9523 & $\mathbf{0 . 9 6 6 9}$ & 0.776 & Korsemeyer-peppas \\
$\mathrm{F}_{3}$ & 0.9048 & 0.9476 & 0.8991 & $\mathbf{0 . 9 6 1 4}$ & 0.9461 & 0.738 & Hixon-crowell \\
$\mathrm{F}_{4}$ & 0.9492 & 0.967 & 0.896 & $\mathbf{0 . 9 7 8 3}$ & 0.9684 & 0.812 & Hixon-crowell \\
$\mathrm{F}_{5}$ & 0.9295 & 0.9471 & 0.8899 & $\mathbf{0 . 9 6 8}$ & 0.9545 & 0.79 & Hixon-crowell \\
$\mathrm{F}_{6}$ & 0.7511 & 0.9588 & 0.9944 & 0.9161 & $\mathbf{0 . 9 9 4 5}$ & 0.492 & Korsemeyer-peppas \\
$\mathrm{F}_{7}$ & 0.8065 & 0.9587 & 0.9388 & $\mathbf{0 . 9 6 5 3}$ & 0.946 & 0.581 & Hixon-crowell \\
$\mathrm{F}_{8}$ & 0.6639 & 0.9713 & 0.9838 & 0.9776 & $\mathbf{0 . 9 8 8 9}$ & 0.441 & Korsemeyer-peppas \\
$\mathrm{F}_{9}$ & 0.371 & 0.9749 & 0.9294 & 0.9655 & $\mathbf{0 . 9 9 4 1}$ & 0.313 & Korsemeyer-peppas \\
\hline
\end{tabular}

\subsection{Optimization of lornoxicam pellets by central composite design}

A central composite design was used to optimize the pellets by studying the effect of independent variables (concentration of copal gum $\left(X_{1}\right)$ and concentration of pectin $\left(X_{2}\right)$ on the dependent variable (cumulative percentage drug released at $10 \mathrm{~h}(\mathrm{Q} 10)$, time required to release drug $\left(\mathrm{t}_{50}\right)$, \% yield and average pellets size. The results of these factors were extensively influenced by the combination of different independent variables as shown in Table 4.

Table 4. Effect of factors on responses variables.

\begin{tabular}{ccccccc}
\hline \multirow{2}{*}{ Batch } & $\mathbf{X}_{\mathbf{1}}$ & $\mathbf{X}_{\mathbf{2}}$ & $\mathbf{Y}_{\mathbf{1}}$ & $\mathbf{Y}_{\mathbf{2}}$ & $\mathbf{Y}_{\mathbf{3}}$ & $\mathbf{Y}_{\mathbf{4}}$ \\
\cline { 2 - 7 } & $\begin{array}{c}\text { Conc. of copal } \\
\text { gum (mg) }\end{array}$ & $\begin{array}{c}\text { Conc. of } \\
\text { pectin }(\mathbf{m g})\end{array}$ & $\begin{array}{c}\text { \% drug release at } \\
\mathbf{1 0} \mathbf{h}(\mathbf{Q 1 0})\end{array}$ & $\begin{array}{c}\mathbf{t}_{50} \\
\mathbf{( h )}\end{array}$ & $\begin{array}{c}\text { \% } \\
\text { yield }\end{array}$ & $\begin{array}{c}\text { Particle size } \\
(\boldsymbol{\mu m})\end{array}$ \\
\hline $\mathrm{F}_{1}$ & 1.50 & 1.00 & 77.37 & 6.13 & 79 & 752.577 \\
$\mathrm{~F}_{2}$ & 1.00 & 1.50 & 96.03 & 5.019 & 60 & 837.212 \\
$\mathrm{~F}_{3}$ & 1.50 & 1.71 & 79.68 & 6.07 & 72.2 & 920.829 \\
$\mathrm{~F}_{4}$ & 1.50 & 0.29 & 69.43 & 6.86 & 80 & 990.123 \\
$\mathrm{~F}_{5}$ & 2.21 & 1.00 & 81.67 & 6.02 & 70.4 & 818.024 \\
$\mathrm{~F}_{6}$ & 2.00 & 0.50 & 65.79 & 6.99 & 80.8 & 990.416 \\
$\mathrm{~F}_{7}$ & 2.00 & 1.50 & 82.33 & 5.41 & 67.2 & 814.573 \\
$\mathrm{~F}_{8}$ & 1.00 & 0.50 & 101.99 & 4.71 & 81.6 & 895.944 \\
$\mathrm{~F}_{9}$ & 0.79 & 1.00 & 101.64 & 4.48 & 80.2 & 830.44 \\
\hline
\end{tabular}

From the ANOVA results, the responses $Y_{1}, Y_{2}, Y_{4}$, the quadratic effect $\left(X_{1}^{2}, X_{2}{ }^{2}\right)$ and linear effect $\left(X_{1}\right.$ copal gum, $X_{2}$ - pectin) are significant while for response $Y_{3}$, no model is significant. The application of response surface methodology was obtained the following regression equations (Eq. 1-4);

$$
\begin{aligned}
& Y_{1}=77.37-9.7 X_{1}+3.13 X_{2}+5.63 X_{1} X_{2}+8.00 X_{1}^{2}-0.55 X_{2} \\
& Y_{2}=0.613+0.61 X_{1}-0.30 X_{2}-0.47 X_{1} X_{2}-0.52 X_{1}^{2}+0.086 X_{2}{ }^{2} \\
& Y_{3}=79.00-0.93 X_{1}-5.78 X_{2}+2.00 X_{1} X_{2}-2.67 X_{1}^{2}-2.27 X_{2}{ }^{2} \\
& Y_{4}=752.58+6.78 X_{1}-41.57 X_{2}-29.28 X_{1} X_{2}+34.50 X_{1}{ }^{2}+100.12 X_{2}{ }^{2}
\end{aligned}
$$


The impact of independent factors (i.e., copal gum and pectin) at different levels on the in-vitro released at $10 \mathrm{~h}(\mathrm{Q} 10)$, time required to release drug $50 \%\left(\mathrm{t}_{50}\right)$, \% yield and average pellets size is shown in Figure 3. The three dimensional response plots depict a curvilinear relationship between the factors and the response. The linear effect of pectin $\left(\mathrm{X}_{2}\right)$ and quadratic effect of copal gum $\left(\mathrm{X}_{1^{2}}\right)$ were also significant for this response. The polynomial equation of $t_{50}$ indicated that linear effect of copal gum $\left(X_{1}\right)$ and quadratic effect of pectin $\left(X_{2}{ }^{2}\right)$ were significant for selected response. Interactive effect did not show compliance according to equation study. The polynomial equation of particle size indicated that quadratic effect of both copal gum $\left(\mathrm{X}_{1}^{2}\right)$ and pectin $\left(\mathrm{X}_{2}{ }^{2}\right)$ and linear effect of copal gum $\left(\mathrm{X}_{1}\right)$ were significant for particle size response. From the polynomial equation of $Y_{1}$ (Eq. 1), it is clearly evident that as the \% of copal gum (-9.7 $\left.X_{1}\right)$ increases, $Y_{1}$ (Drug release at 10 hrs) decreases.
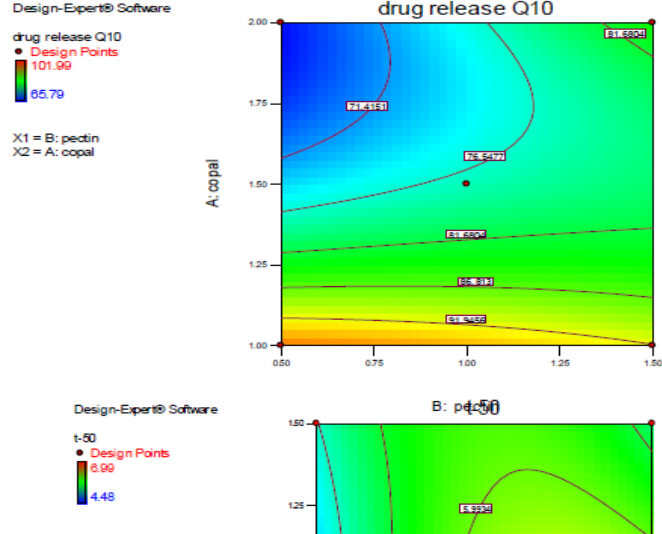

$x_{1}=A:$ copal
$x_{2}=B:$ pectin
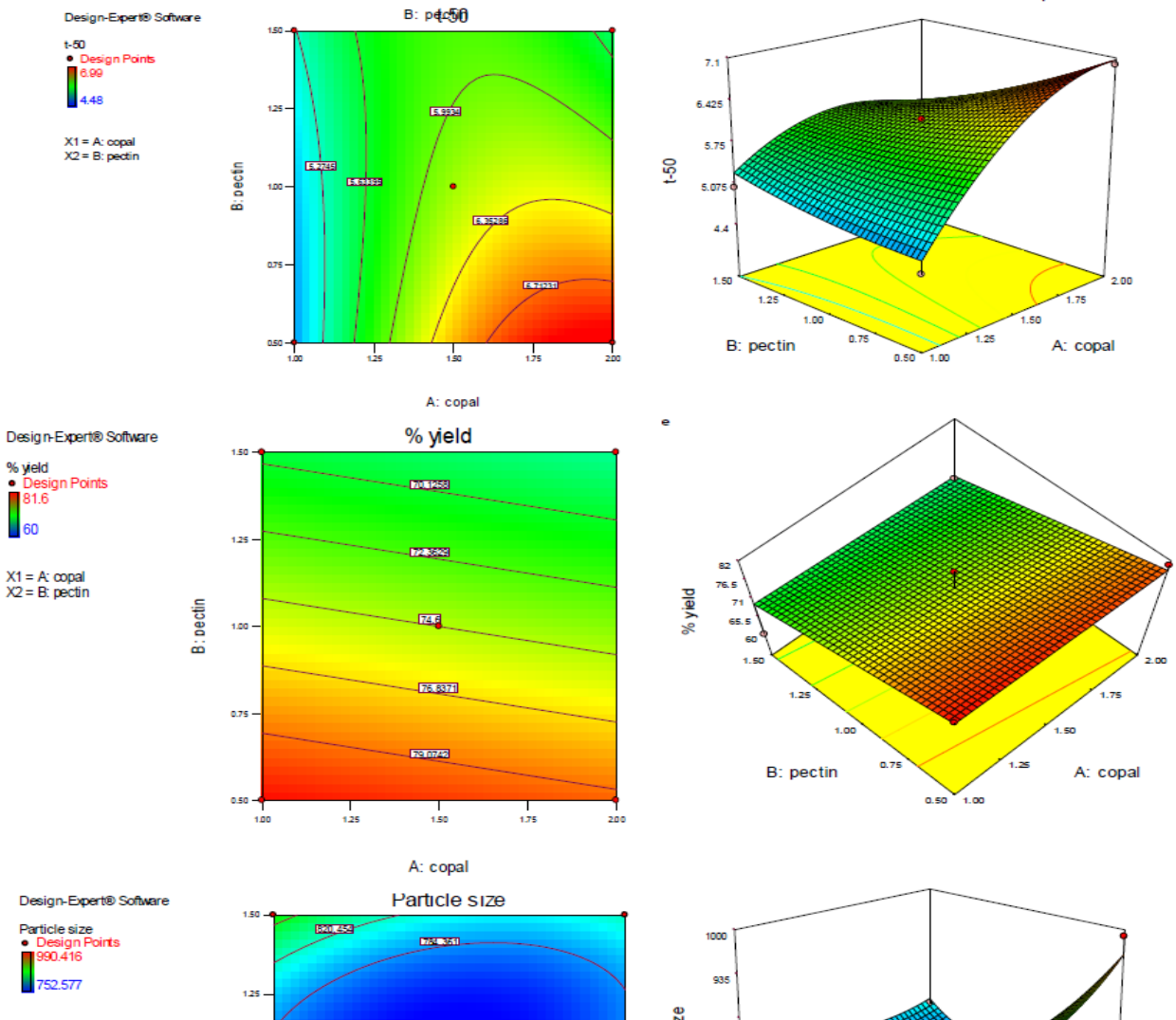

$X_{1}=A \cdot$ copol
$X_{2}=B:$ pectin
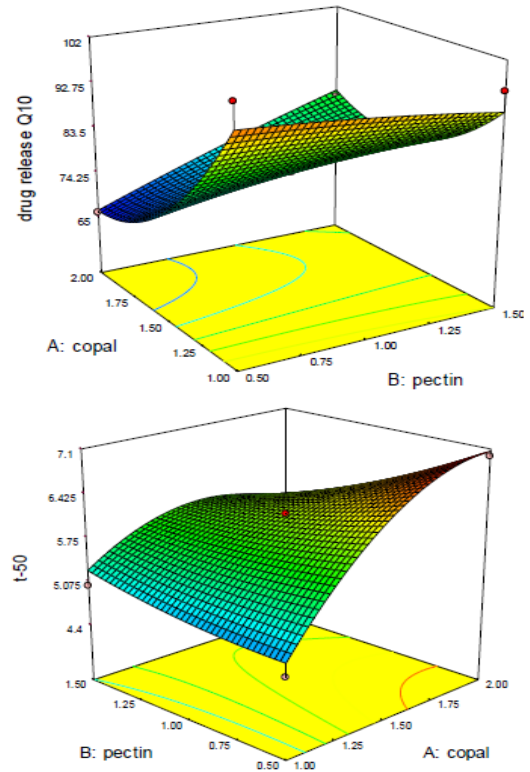
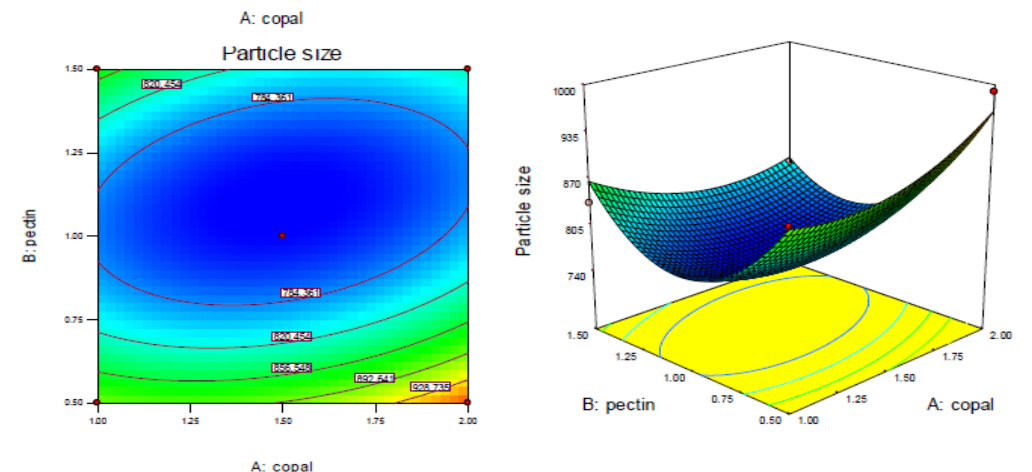

Figure 3. Contour and response surface plots showing influence of independent variables on percent cumulative drug release $(\% \mathrm{CDR})$ at $10 \mathrm{th} \mathrm{hr}\left(\mathrm{Y}_{1}\right)$, time required to release drug $50 \%\left(\mathrm{t}_{50}\right)\left(\mathrm{Y}_{2}\right)$, \% yield $\left(\mathrm{Y}_{3}\right)$ and average pellets size $\left(\mathrm{Y}_{4}\right)$. 
Moreover, an effect of independent variable $X_{1}$ is more dominant factor than $X_{2}$ at $Y_{1}$. The polynomial equation of drug release indicated that interactive effect $\left(X_{1} X_{2}\right)$ was significant. It was observed from the regression equation that the independent variable copal gum has a negative effect on $Y_{1}$. This proves that an increasing amount of copal gum leads to a decrease in the drug release, i.e. near to unity, which is desirable. On $Y_{1}$ and $Y_{2}$ a positive effect of pectin was observed. As the concentration of pectin increases the drug release of pellets also increases. From the polynomial equation of $Y_{2}$, copal gum has a synergistic effect on time required to $50 \%$ release of lornoxicam, whereas pectin has an antagonistic effect as described in Eq. 2 . Furthermore, copal gum and pectin exhibit a synergistic interaction on the release of drug as can be seen from the positive value of the coefficient for this factor. Similarly, copal gum and pectin have an antagonistic effect each other on percent yield (Eq. 3) where as both have an oppositely effect on average particle size as described in Eq. 4. From the results of regression analysis it was concluded that all the two independent factors significantly contributed to Q10 $(P<0.05)$.

From Figure 3, the drug release at $10 \mathrm{~h}(\mathrm{Q} 10)$ showed linear and quadratic relation in the concentation of copal and pectin on the drug release at $10 \mathrm{~h}$. It was observed that increase in the concentration of both copal and pectin, increases the drug release at $10 \mathrm{~h}$. At the same time it shows that when copal is constat between the range of 1 to 1.25 and pectin gets incresses, the drug release at $10 \mathrm{~h}$ also gets increases. The half life $\left(t_{50}\right)$ showed linear and quadratic relation in the concentation of copal and pectin. When the concentration of both decrease, $t_{50}$ also decreases. At the same time it can be interprete that, if the copal concentration is in maximum range and pectin concentration is in the range of 0.50 to $1.00, \mathrm{t}_{50}$ gets increases. \% yield shows only linear effect of concentarion of copal and pectin. It shows that increase in the concentration of both copal and pectin, increases the \% yield. Particle size showed only quadratic effect of concentarion of copal and pectin. It shows that if the concentration of copal and pectin increses, the particle size decreases. As the concentration of copal increases and concentration of pectin decreases, the particle size will be increases. For validation of RSM results, the experimental values of the responses were compared with that of the anticipated values and the prediction error was found to vary between $-0.468 \%$ and $1.212 \%$. The linear correlation plots drawn between the predicted and experimental values demonstrated high values of $r^{2}$ (1 to 0.998) indicating excellent goodness of fit $(p<0.001)$. Thus the low magnitudes of error as well as the significant values of $\mathrm{r}^{2}$ in the present investigation prove the high prognostic ability of the RSM. The experimental values were in agreement with the predicted values confirming the predictability and validity of the model [14-15].

The optimized sustained released pellets formulation was obtained by applying constraints on dependent variable responses and independent variables. The constraints were $Q 10>80 \%, \mathrm{t}_{50}>5.0 \mathrm{~h}, \%$ yield $>70$ and particle size $<850$. These constrains are common for all the formulations. The recommended concentrations of the independent variables were calculated by the design expert software from the above plots which has the highest desirability near to 1.0 [14]. The extensive grid and feasibility searches provided that the optimum formulations and the desired function response overlay plot, where one solution was found with a highest desirability. Graphical optimization and point prediction showed same prediction values. The graphical representation helped for easy interpretation of results. Among the pellet batches $\mathrm{F}_{7}$ was found to be optimized based on the criteria of attaining minimum drug released in $8 \mathrm{~h}$, maximum percent yield. The $\mathrm{F}_{1}$ (dissimilarity value) and $\mathrm{F}_{2}$ (similarity value) for drug release at $30 \pm 2^{\circ} \mathrm{C} / 65 \pm 5 \% \mathrm{RH}$ were 4.74 and 73.44 respectively while for drug release at $40 \pm 2^{\circ} \mathrm{C} / 75 \pm 5 \% \mathrm{RH}$ were 3.75 and 77.89 respectively indicated that the formulation was stable after six month and complied for the stability. The drug content gave the correlation coefficient values of 0.9957 and 0.9933 for conditions at $30 \pm 2^{\circ} \mathrm{C} / 65 \pm 5 \% \mathrm{RH}$ and at $40 \pm 2^{\circ} \mathrm{C} / 75 \pm 5 \% \mathrm{RH}$ respectively which indicated that the values were strongly correlated with each other. From stability study it was concluded that there were no major changes in the physicochemical parameters evaluated like drug content and in-vitro dissolution pattern at the various sampling points.

\section{CONCLUSION}

The results of the present study indicated that a use of central composite design, the screening study confirmed concentration of polymers could influence the pellets properties. The pragmatic responses for the optimum formulation were in close concurrence with the predicted values, demonstrating the excellent predictability of the optimization procedure. The sustained release lornoxicam pellets were $2 \mathrm{mg}$ copal gum and $1.5 \mathrm{mg}$ pectin fulfilled the optimal criteria of best regulation of the release rate and production yield characteristics with Q10 of $83.20 \%$, $\mathrm{t}_{50}$ of $5.13 \mathrm{~h}$, percent yield of $67.52 \%$ and particle size of $820.24 \mu \mathrm{m}$. 


\section{MATERIALS AND METHODS}

Lornoxicam was a kind gift provided by Pure Chem Pvt. Ltd., Gujarat, India. Pectin and Copal gum was procured from Maple Biotech Pvt. Ltd., Pune and Hans Chemicals, Nagpur, respectively. MCC 101 was obtained as gift sample from Gebbs pharmaceutical Pvt. Ltd., Nasik. All other reagents and chemicals were of analytical quality.

\subsection{Preparation method for lornoxicam pellets by extrusion and spheronization}

A powder mixture of lornoxicam, polymers and microcrystalline cellulose (MCC) was gradually mixed in a mortar for $20 \mathrm{~min}$. This was followed by addition of binding liquid consisting of $10 \%$ PEG 4000 in water until a homogeneous, cohesive blend mass. The resultant wet mass was passed through BSS sieve no. 16 at the speed of $18 \mathrm{rpm}$ to obtain the extrudates. The prepared extrudates were then transferred to a spheronizer (VJ Instrument, Karanja, Maharashtra) and spheronized at 200-300 rpm spheronizing speed for 10 to 15 min to get pellets. From the speed of spheronizer machine, size of pellet was determined. Increase in spheronizer speed decreases the pellets size. The prepared pellets were oven dried overnight at $60^{\circ} \mathrm{C}$ [16-17].

\subsection{Experimental central composite design for sustained release lornoxicam pellets formulation}

A 9-run experimental central composite design was adopted to optimize levels of variables in the pellet formulations. The selected independent variables were amounts of copal gum $\left(X_{1}\right)$, and of pectin $\left(X_{2}\right)$ and low level is coded as +1 and -1 respectively (Table 1$)$. The dependent variables were drug release at $10 \mathrm{~h}\left(\mathrm{Y}_{1}\right)$ so as to predict the sustainability, time required to release $50 \%$ (half life) of drug $\left(\mathrm{Y}_{2}\right)$, \% yield $\left(\mathrm{Y}_{3}\right)$ and pellets size $\left(\mathrm{Y}_{4}\right)$. The generation of experimental runs, ANOVA study and optimization were carried out by designexpert ${ }^{\circledR}$ software 9. The contribution of the different formulation variable was compared using analysis of variance (ANOVA) at $\left(\begin{array}{ll}P & 0.05\end{array}\right)$ significance level. The statistical model incorporating interactive and polynomial term was used to evaluate the responses (Eq 5).

$$
\mathrm{Y}=\mathrm{B}_{0}+\mathrm{B}_{1} \mathrm{X}_{1}+\mathrm{B}_{2} \mathrm{X}_{2}+\mathrm{B}_{12} \mathrm{X}_{1} \mathrm{X}_{2}+\mathrm{B}_{11} \mathrm{X}_{1}^{2}+\mathrm{B}_{22} \mathrm{X}_{2}^{2}
$$

Where $\mathrm{Y}$ is dependent variable, $\mathrm{B}_{0}$ is the arithmetic mean response of the 9 runs; $\mathrm{B}_{1}$ is the estimated coefficient factor $X_{1}$. The main effects $\left(X_{1}\right.$ and $\left.X_{2}\right)$ represent the average result of changing one factor at a time from its low to high value. The interaction term $\left(X_{1} X_{2}\right)$ shows the how response changes when two factors simultaneously changed.

\subsection{Fourier transform infrared spectrum}

The FTIR spectrums of lornoxicam, copal gum and pectin, and physical mixture of lornoxicam and polymers were recorded on samples prepared in potassium bromide (KBr) disks using FTIR spectrophotometer (Model-1601 PC, Shimadzu Corporation, Japan). The scanning range for sample was 400 to $4000 \mathrm{~cm}^{-1}[10]$.

\subsection{Physical micromeritic characterization}

The micromeritic properties of pellets were characterized by analyzing bulk density, tapped density, carr's index, hausner's ratio, angle of repose [18]. Friability of the pellets was determined using a USP friability test apparatus. Friability was determined as the percentage of weight loss from pellet formulations after 200 revolutions of $6.5 \mathrm{~g}$ of the pellets in a friabilator (Roche Friability Tester, India) [19]. The hardness of the pellets was determined using a digital hardness tester (Veego, India).

\subsection{Particle size distribution}

The size distribution of the pellets was determined using a mechanical sieve shaker (Make-Kumar). A series sieve of no. 8, 10,16, 22, 36, 44, and 44 were arranged in order of decreasing aperture size. An accurately weighed amount of pellets from each batch was placed on the uppermost sieve. The sieves were shaken for 10 min and the material retained on each sieve was weighed separately. A graph of mean size vs. \% weight retained was plotted to analyze pellet size distribution [19-20]. 


\subsection{Percent yield}

The pellets recovered at the end of preparation were weighted and yield of pellets was calculated by following formula (Eq 6);

$\%$ yield $=\left(P_{m} / T_{m} \times 100\right)$

[Eq. 6]

Where, $P_{\mathrm{m}}$ is practical yield and $T_{\mathrm{m}}$ is theoretical yield of formulated pellets.

\subsection{Drug content}

Lornoxicam pellets equivalent to the dose of lornoxicam drug $(16 \mathrm{mg})$ were ground using a mortar and pestle and transferred into a $100 \mathrm{ml}$ volumetric flask containing $0.05 \mathrm{~N}$ sodium hydroxide and the volume was made up to $100 \mathrm{ml}$. The mixture was sonicated for $15 \mathrm{~min}$ to ensure complete extraction of the drug. The solution was filtered through Whatman filter paper and assayed spectrophotometrically (Shimadzu 1700, Japan) at $376 \mathrm{~nm}$ to determine the percent drug content by using standard calibration curve of lornoxicam in $0.05 \mathrm{~N}$ sodium hydroxide solutions [4].

\subsection{In-vitro drug release and kinetics studies}

Drug release studies of the lornoxicam pellets were performed by USP Dissolution Apparatus-I (Veego DA-8D, India). The dissolution studies were carried out with $900 \mathrm{ml}$ of potassium phosphate buffer ( $\mathrm{pH}$ 7.4) as dissolution medium at $37 \pm 0.5^{\circ} \mathrm{C}$ and at $50 \mathrm{rpm}$. Pellets equivalent to $16 \mathrm{mg}$ of lornoxicam were weighed and transferred to the dissolution apparatus. A $10 \mathrm{ml}$ aliquot was withdrawn and replaced by the same volume of fresh medium to maintain sink condition. The aliquot was filtered through Whatman filter paper and absorbance was measured at $376 \mathrm{~nm}$ using a UV spectrophotometer (Shimadzu 1700, Japan) to determine the drug release [21]. Cumulative percentage of drug release was calculated using an equation obtained from a standard curve. The drug in potassium phosphate buffer $(\mathrm{pH} 7.4)$ followed Beer-Lambert's law in the range of $5-30 \mu \mathrm{g} / \mathrm{ml}$ with correlation co-efficient of 0.998 . In order to describe the kinetics of drug release from sustained released pellets formulation; various mathematical equations have been used like zero order, first order, higuchi model, hixson-crowell cube root law and korsmeyer peppas equation. The program DD-Solver was used to analyze model dependent kinetics [14].

\subsection{Response surface, overlay plot and validation of model [15]}

The quadratic model obtained from regression analysis is used to build 3 dimensional graphs. The dependent variable $(Y)$ was represented by a curvature surface as a function of $X_{1}$. The relationship between the dependent and independent variables was elucidated using response surface plots. Optimization was based on the criteria of attaining the minimum particle size $(<895.95 \mu \mathrm{m})$, the maximum value of drug released $82 \%$ in $10 \mathrm{~h}, \mathrm{t}_{50}$ in $6 \mathrm{~h}$ and \% yield in range of $60-80 \%$. In point prediction, various solutions were given by the software according to criteria fitted for all the responses. All solutions were expected to give the results in selected range. The solutions given by the software in point prediction were shown in graphical form. This was helpful to interpret the solutions given by the software for expected results. The experimental results of selected optimized batch and results predictes by the software for selected responses were compared and analysed. The study of correlation coefficient $\left(\mathrm{r}^{2}\right)$ value was used for analysis.

\subsection{Stability studies}

The stability studies of pellets were studied using the reported standard procedure at different temperatures. The pellets were wrapped in aluminum foil and placed in petri dishes. These containers were stored at ambient humid conditions, at intermediate temperature $\left(30 \pm 2^{\circ} \mathrm{C} / 65 \pm 5 \% \mathrm{RH}\right)$ and accelerated condition $\left(40 \pm 2^{\circ} \mathrm{C} / 75 \pm 5 \%\right)$ for a period of 6 months. The samples were analyzed for physical changes such as color, texture, drug content and drug release characteristics and compared with the initial values before storage. The $F_{1}$ (dissimilarity value) and $F_{2}$ (similarity value) were calculated for drug release parameter by using DD-solver tool while the value of correlation coefficient was calculated for drug content [22]. 
Acknowledgements: Authors acknowledges Pure Chem Pvt. Ltd., Gujarat, India for providing the gift sample of lornoxicam. The authors are thankful to Principal, Government College of Pharmacy, Amravati for providing technical assistance and necessary facilities to carry out the research work.

Author contributions: Concept - M.S., P.D.; Design - M.S., P.D.; Supervision - M.S.; Resources - M.S.; Materials - M.S., P.D.; Data Collection and/or Processing - M.S., P.D.; Analysis and/or Interpretation - M.S., P.D.; Literature Search M.S., P.D.; Writing - M.S.; Critical Reviews - M.S., P.D.

Conflict of interest statement: The authors declared no conflict of interest.

\section{Appendix A. Supplementary Material}

Supplementary material related to this article can be accessed at http://doi.org/10.35333/jrp.2020.225.

\section{REFERENCES}

[1] Patel PB, Dhake AS. Multiparticulate approach: an emerging trend in colon specific drug delivery for Chronotherapy. J Appl Pharm Sci. 2011; 1(5): 59-63.

[2] Schwartz JB, Connor RE, Schnaare RL. Optimization techniques in pharmaceutical formulation and processing. Modern pharmaceutics. CRC Press, 2002, pp. 921-950.

[3] Sivasankar M, Krishna M, Sunitha R. Formulation, evaluation and optimization of sustained release microcapsules of lornoxicam prepared with gum dikamali and pectin extracted from Dillenia Indica. Int J Chem Sci. 2015; 13(1): 97106.

[4] Ulla SN, Roy AK, Kulkarni M, Kumar SM. Formulation and evaluation of sustained release matrix tablets of lornoxicam. Int J Drug Dev Res. 2011; 1(3): 31-44.

[5] Basak N, Aksoy Y, Kaydu A, Sahin OF. Lornoxicam use to reduce the pain associated with propofol injection. Libyan J Med. 2017; 12(1): 1313093. [CrossRef]

[6] Kalyanappa S, Krishna MR, Goli D. Design and in-vitro evaluation of a novel sustained release double layered tablets of lornoxicam by using semi synthetic polymers. Indian J Pharm Educ. 2015; 49(4): 281-291. [CrossRef]

[7] Hamza YE, Aburahma MH. Design and in-vitro evaluation of novel sustained-release matrix tablets for lornoxicam based on the combination of hydrophilic matrix formers and basic pH-modifiers. Pharm Dev Technol. 2010; 15(2): 139-153. [CrossRef]

[8] Pagar R, Patil D, Pawar P, Ghule RS, Bairagi VA. Formulation and development of sustained release matrix tablets of lornoxicam. J Drug Deliv Ther. 2018; 8(2): 102-106. [CrossRef]

[9] Gupta MM, Ray B. A review on sustained release technology. Int J Ther Appl. 2012; 8: 1-23.

[10] Hamza YE, Aburahma MH. Design and in-vitro evaluation of novel sustained-release double-layer tablets of lornoxicam: utility of cyclodextrin and xanthan gum combination. AAPS PharmSciTech. 2009; 10(4): 1357. [CrossRef]

[11] Mehta KA, Kislaloglu MS, Phuapradit W. Release performance of poorly soluble drug from a novel Eudragit based multi-unit erosion matrix. Int J Pharm. 2001; 213: 7-12. [CrossRef]

[12] Korsmeyer R, Gurny R, Peppas N. Mechanisms of solute release from porous hydrophilic polymers. Int J Pharm. 1983; 15: 25-35. [CrossRef]

[13] Kostewicz ES, Abrahamsson B, Brewster M, Brouwers J, Butler J, Carlert S, Dickinson PA, Dressman J, Holm R, Klein S, Mann J. In-vitro models for the prediction of in-vivo performance of oral dosage forms. Eur J Pharm Sci. 2014; 57: 342-366. [CrossRef]

[14] Shende MA, Marathe RP. Development and optimization of oral gastroadhesive matrices for diltiazem hydrochloride using some natural materials. Res J Pharm Technol. 2016; 9(7): 817-830. [CrossRef]

[15] Singh G, Pai RS, Devi VK. Response surface methodology and process optimization of sustained release pellets using Taguchi orthogonal array design and central composite design. J Adv Pharm Technol Res. 2012; 3(1): 30. [CrossRef]

[16] Lavanya K, Senthil V, Rathi V. Pelletization technology: a quick review. Int J Pharm Sci Res. 2011; 2(6): 1337-1355.

[17] Morkhade DM, Fulzele SV, Satturwar PM, Joshi SB. Gum copal and gum damar: novel matrix forming materials for sustained drug delivery. Indian J Pharm Sci. 2006; 68(1): 53-58. [CrossRef]

[18] Pagariya TP, Patil SB. Development and optimization of multiparticulate drug delivery system of alfuzosin hydrochloride. Colloids Surf B. 2013; 102: 171-177. [CrossRef] 
[19] Tubati VP. Formulation development and statistical optimization of ivabradine hydrochloride floating pulsatile microspheres using response surface methodology. Asian J Pharm. 2016; 10(2): 1-11.

[20] Patil SM, Mishra RV, Shirolkar SV. Development and evaluation of sustain release simvastatin pellets. Res J Pharm Technol. 2017; 10(8): 2467-2473. [CrossRef]

[21] Gonullu U, Gurpinar P, Uner M. Double-layer tablets of lornoxicam: validation of quantification method, in-vitro dissolution and kinetic modelling. Trop J Pharm Res. 2015; 14(9): 1659-1666.

[22] ICH Topic Q1A (R2): Note for guidance on stability testing: stability testing of new drug substances and products. 2003; CPMP/ICH/2736/99. https://database.ich.org/sites/default/files/Q1A\%28R2\%29\%20Guideline.pdf (accessed on 18 July 2018).

This is an open access article which is publicly available on our journal's website under Institutional Repository at http://dspace.marmara.edu.tr. 